\title{
Evaluation of phlorofucofuroeckol-A isolated from Ecklonia cava (Phaeophyta) on anti-lipid peroxidation in vitro and in vivo
}

\author{
Ji-Hyeok Lee ${ }^{1}$, Ju-Young Ko ${ }^{1}$, Jae-Young $\mathrm{Oh}^{1}$, Eun-A Kim ${ }^{1}$, Chul-Young Kim ${ }^{2}$ and \\ You-Jin Jeon ${ }^{1, *}$
}

${ }^{1}$ Department of Marine Life Science, Jeju National University, Jeju 63243, Korea

${ }^{2}$ Natural Product Research Center, Hanyang University, Ansan 15588, Korea

\begin{abstract}
Lipid peroxidation means the oxidative degradation of lipids. The process from the cell membrane lipids in an organism is generated by free radicals, and result in cell damage. Phlorotannins, well-known marine brown algal polyphenols, have been utilized in functional food supplements as well as in medicine supplements to serve a variety of purposes. In this study, we assessed the potential anti-lipid peroxidation activity of phlorofucofuroeckol-A (PFF-A), one of the phlorotannins, isolated from Ecklonia cava by centrifugal partition chromatography in 2,2-azobis (2-amidinopropane) dihydrochloride (AAPH)-stimulated Vero cells and zebrafish system. PFF-A showed the strongest scavenging activity against alkyl radicals of all other reactive oxygen species (ROS) and exhibited a strong protective effect against ROS and a significantly strong inhibited of malondialdehyde in AAPH-stimulated Vero cells. The apoptotic bodies and pro-apoptotic proteins Bax and caspase-3, which were induced by AAPH, were strongly inhibited by PFF-A in a dose-dependent manner and expression of Bcl-xL, an anti-apoptotic protein, was induced. In the AAPH-stimulated zebrafish model, additionally PFF-A significantly inhibited ROS and cell death, as well as exhibited a strong protective effect against lipid peroxidation. Therefore, these results suggest that PFF-A has excellent protective effects against ROS and lipid peroxidation induced by AAPH in both an in vitro Vero cell model and an in vivo zebrafish model.
\end{abstract}

Key Words: AAPH; Ecklonia cava; lipid peroxidation; phlorofucofuroeckol-A; Vero cell model; zebrafish model

\section{INTRODUCTION}

Lipid peroxidation generates oxygen free-radicals as well as metabolites in various cell injuries and under many pathological conditions (Esterbauer et al. 1992, Halliwell et al. 1992). In the presence of oxygen, lipid peroxidation induced by the peroxyl radicals (ROO·) contributes to adverse changes in bio-membrane composition such as attacking membrane polyunsaturated fatty acids, initiating lipid peroxidation chain reactions, leading to an interference with cell-signaling pathways, and ultimately to loss of cell function and viability (Bast et al. 1991, Hu and Kitts 2005). Many researchers have studied natural compounds with anti-lipid peroxidation activity as an alternative to the synthesis of compounds that produce various side effects (Jain et al. 2003, Faure et al. 2004, Ling et al. 2012).

Ecklonia cava Kjellman, an edible brown seaweed, grows prolifically along the Coast of Jeju Island in South Korea. In previous studies, phlorotannins from E. cava
(9) $\$$ This is an Open Access article distributed under the terms of the Creative Commons Attribution Non-Commercial License (http://creativecommons.org/licenses/by-nc/3.0/) which permits unrestricted non-commercial use, distribution, and reproduction in any medium, provided the original work is properly cited.
Received August 30, 2015, Accepted November 13, 2015

*Corresponding Author

E-mail: youjin2014@gmail.com

Tel: +82-64-754-3475, Fax: +82-64-756-3493 
have been proved were shown to be responsible for antioxidant, antimicrobial, anti-obesity, anti-elastase, antiallergy, anti-inflammatory, and anti-human immunodeficiency virus activities (Artan et al. 2008, Le et al. 2009, Eom et al. 2012, Kang et al. 2012b, Ko et al. 2013, Kim 2014). One of the phlorotannins, phlorofucofuroeckolA (PFF-A) was reported to have antioxidative and antiinflammatory activities recently and it has been known to regulate IgE-mediated allergic reactions ( $\mathrm{Li}$ et al. 2009, Shim et al. 2009, Kim et al. 2011). However, the anti-lipid peroxidation effect of PFF-A has not been yet examined.

In this study therefore, we investigated whether PFFA has a protective effect against lipid peroxidation induced by $2,2^{\prime}$-azobis (2-amidinopropane) hydrochloride (AAPH) treatment in Vero cells (monkey kidney cell line) and a zebrafish system.

\section{MATERIALS AND METHODS}

\section{Materials}

E. cava collected on the coast of Jeju island, south Korea in June 2013, was ground and shifted through a 50 mesh standard testing sieve after dried by freeze dryer SFDSMO6 (Samwon freezing engineering Co., Busan, Korea), and then the dried E. cava was stored in refrigerator until use.

All solvents used for preparation of crude sample and centrifugal partition chromatography (CPC) separation were of analytical grade (Daejung Chemicals \& Metals Co., Seoul, Korea). High-performance liquid chromatography grade solvents were purchased from Burdick \& Jackson (Muskegon, MI, USA).

\section{Preparation of PFF-A from Ecklonia cava ethano- lic extract}

Dried E. cava (20 g) was extracted three times for $3 \mathrm{~h}$ using $70 \% \mathrm{EtOH}$ under sonication at room temperature. The extract was concentrated in a rotary vacuum evaporator and partitioned with ethyl acetate (EtOAc), and then the dried EtOAc fraction was stored in a refrigerator for CPC separation. The isolation of PFF-A by CPC experiments were performed as our previous paper (Lee et al. 2014) and its structure was shown in Fig. 1. Identification of the compound (136.4 mg) obtained from $20 \mathrm{~g} E$. cava was carried out using proton nuclear magnetic resonance $\left({ }^{1} \mathrm{H} \mathrm{NMR}\right)$, carbon nuclear magnetic resonance $\left({ }^{13} \mathrm{C}\right.$ NMR), and high-performance liquid chromatography-

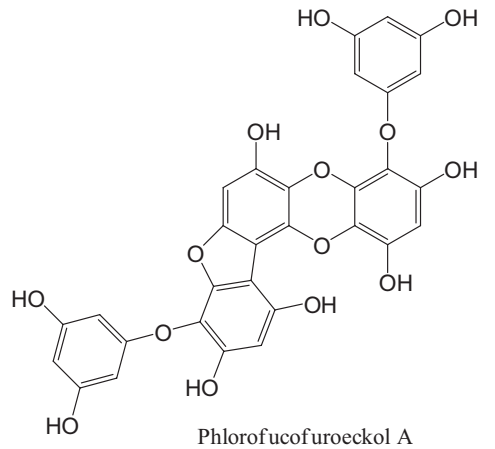

Fig. 1. Chemical structure of the phlorofucofuroeckol-A.

diode array detection-electrospray ion trap tandem mass spectrometry (HPLC-DAD-ESI/MS) (negative ion mode) analyses.

PFF-A: amorphous powder, ${ }^{1} \mathrm{H}$ NMR $(400 \mathrm{MHz}$, methanol-d4) d: $6.63(1 \mathrm{H}, \mathrm{s}, \mathrm{H}-7), 6.40(1 \mathrm{H}, \mathrm{s}, \mathrm{H}-11), 6.26(1 \mathrm{H}$, s, H-2), $5.97(2 \mathrm{H}, \mathrm{d}, \mathrm{J}=2.1 \mathrm{~Hz}, \mathrm{H}-200,600), 5.94(1 \mathrm{H}, \mathrm{t}, \mathrm{J}=$ $1.9 \mathrm{~Hz}, \mathrm{H}-40), 5.92(1 \mathrm{H}, \mathrm{t}, \mathrm{J}=2.0 \mathrm{~Hz}, \mathrm{H}-400), 5.88(2 \mathrm{H}, \mathrm{d}, \mathrm{J}$ $=2.1 \mathrm{~Hz}, \mathrm{H}-20,60) .{ }^{13} \mathrm{C}$ NMR (100 MHz, CD3OD) d: 162.7, 162.6, 161.0, 161.0, 154.0, 152.5, 152.0, 149.1, 149.0, 146.7, $144.7,139.2,136.2,128.9,125.9,125.6,123.2,106.2,106.1$, 100.8, 100.2, 98.6, 98.5, 97.0, 96.2, 96.2; ESI-MS: [M-H] ${ }^{-}$at $\mathrm{m} / \mathrm{z} 601.36$

\section{Radical scavenging assay by electron spin reso- nance (ESR)}

The variable radicals such as 2,2-diphenyl-1-picrylhydrazyl (DPPH), hydroxyl and alkyl radicals were tested according to the previously described methods (Lee et al. 2013), and the spin adducts were recorded using a JES-FA ESR spectrometer (JES-FA ESR; JEOL, Tokyo, Japan).

\section{Vero cell culture}

A Vero cell line was cultured in Dulbecco's modified Eagle's medium containing $10 \%$ heat-inactivated calf serum, streptomycin $\left(100 \mu \mathrm{g} \mathrm{mL}^{-1}\right)$ and penicillin (100 unit $\left.\mathrm{mL}^{-1}\right)$ at $37^{\circ} \mathrm{C}$ in an incubator, under a humidified atmosphere containing $5 \% \mathrm{CO}_{2}$.

\section{Determination of cell viability and intracellular reactive oxygen species (ROS) generation in Vero cells (dichloro-dihydro-fluorescein diace- tate [DCFH-DA] assay)}

Cell viability was estimated using MTT assay according to the method described by Lee et al. (2015). MTT stock 
solution ( $50 \mu \mathrm{L} ; 2 \mathrm{mg} \mathrm{mL}^{-1}$ ) was added to each of the wells, to a total reation volume of $200 \mu \mathrm{L}$. After $4 \mathrm{~h}$ of incubation time the plates were centrifuged for $5 \mathrm{~min}$ at 1,500 rpm and the supernatant was aspirated. The formazan crystals in each well were dissolved in $150 \mu \mathrm{L}$ of dimethyl sulfoxide and absorbance was measured using enzyme linked immune sorbent assay reader (Sunrise; Tecan Co., Ltd., Salzburg, Australia) at $540 \mathrm{~nm}$. The DCFH-DA method was used to detect the levels of intracellular ROS (Ko et al. 2014). DCFH-DA fluorescence was detected at an excitation wavelength of $485 \mathrm{~nm}$ and the emission wavelength of $535 \mathrm{~nm}$, using a Perkin-Elmer LS-5B spectrofluorometer (Walthman, MA, USA). The DCF fluorescence intensity is proportional to the amount of ROS formed intracellularly. Results are expressed as the percentage of ROS generation as compared to the control.

\section{Determination of lipid peroxidation in Vero cells}

Lipid peroxidation was estimated by measuring spectrophotometrically thiobarbituric acid reacting substances (TBARS) in AAPH treatment or AAPH treated PFF-A. TBARS determination was carried out according to the method of Heath and Parker (1968). Two hundred milligrams of cotyledons were homogenized in $3.5 \mathrm{~mL}$ of distilled water. An equal amount of $0.5 \%$ thiobarbituric acid in $20 \%$ trichloroacetic acid was added and the sample was incubated at $95^{\circ} \mathrm{C}$ for $30 \mathrm{~min}$. The reaction was stopped by transferring the reaction tubes to an ice bucket. The samples were then centrifuged at $8,000 \times g$ for $15 \mathrm{~min}$. The supernatant was taken and absorbance was read at 532 $\mathrm{nm}$ and a value for the non-specific absorption was read at $600 \mathrm{~nm}$. The amount of TBARS (A532 / A600) present was calculated from a calibration curve.

\section{Hoechst 33342 staining assay}

The nuclear morphology of the cells was evaluated using the cell-permeable DNA dye, Hoechst 33342 (Lee et al. 2015). Cells were treated with various concentrations of PFF-A (5.0, 20.8, and $41.5 \mu \mathrm{M})$ and $2 \mathrm{~h}$ later $15 \mathrm{mM}$ of AAPH was added to the culture. After $24 \mathrm{~h}$, the cell treated with final concentration $10 \mu \mathrm{g} \mathrm{mL}^{-1}$ of Hoechst 33342 for $10 \mathrm{~min}$ at $37^{\circ} \mathrm{C}$ in dark. The stained cells were observed under a fluorescence microscope equipped with a CoolSNAP-Pro color digital camera (Olympus, Tokyo, Japan) in order to determine the degree of nuclear condensation.

\section{Western blot analysis}

Vero cells $\left(1 \times 10^{5}\right.$ cells $\left.\mathrm{mL}^{-1}\right)$ were treated with PFF-A (5.0, 20.8, and $41.5 \mu \mathrm{M}$ ) for $2 \mathrm{~h}$ period with treatment of $15 \mathrm{mM}$ AAPH and after $24 \mathrm{~h}$, were harvested. The cell lysates were prepared with lysis buffer $(50 \mathrm{mM}$ Tris- $\mathrm{HCl}[\mathrm{pH}$ 7.4], $150 \mathrm{mM} \mathrm{NaCl}, 1 \%$ Triton X-100, $0.1 \%$ sodium dodecyl sulfate, and $1 \mathrm{mM}$ ethylenediaminetetraacetic acid). Cell lysates were washed via centrifugation, and the protein concentrations were determined using a BCA protein assay kit (Thermo SCIENTIFIC, Rockford, IL, USA). The 30 $\mu$ g of protein were subjected to electrophoresis on $10 \%$ or $12 \%$ sodium dodecyl sulfate-polyacrylamide gels, and the gels were transferred onto nitrocellulose membranes (Bio-Rad, Hercules, CA, USA). The membranes were incubated with primary antibody against Bax, Bcl-xL, cleaved caspase-3, and glyceraldehyde 3-phosphate dehydrogenase in TTBS (25 mM Tris- $\mathrm{HCl}, 137 \mathrm{mM} \mathrm{NaCl}$, and $0.1 \%$ Tween $20, \mathrm{pH}$ 7.4) containing $2 \%$ nonfat dry milk at $1 \mathrm{~h}$. The membranes were then washed with TTBS and incubated with secondary antibodies such as anti-mouse IgG or anti-rabbit IgG (Santa Cruz Biotechnology, Santa Cruz, CA, USA). The blots were developed by enhanced chemiluminescence reagents (iNtRON, Seongnam, Korea) according to the manufacturer's instructions. Band densities of the Western blots were analyzed with MCID Analysis Evaluation 7.0 (Imaging Research Inc., St. Catharines, ON, Canada).

\section{Culture of zebrafish}

Adult zebrafish were purchased from a commercial dealer (Seoul Aquarium, Seoul, Korea) and were kept in a $3 \mathrm{~L}$ acrylic tank at $28.5^{\circ} \mathrm{C}$ with a $14 \mathrm{~h}: 10 \mathrm{~h}$ light-dark cycle. The zebrafish were fed 3 times per day, 6 days per week, with tetramin flake food. Embryos were obtained from natural spawning that was induced in the morning by turning on the light. The collection of embryos was completed within $30 \mathrm{~min}$.

\section{Measurement of total ROS, cell death and lipid peroxidation induced in AAPH-stimulated ze- brafish embryo}

The cell death and ROS was evaluated for antioxidant effects in in vivo zebrafish model by using the protocol described by Ko et al. (2014) and Kang et al. (2013) with a slight modification in zebrafish. Individual zebrafish embryo fluorescence intensity was quantified using a Perkin-Elmer LS-5B spectrofluorometer. The images of 

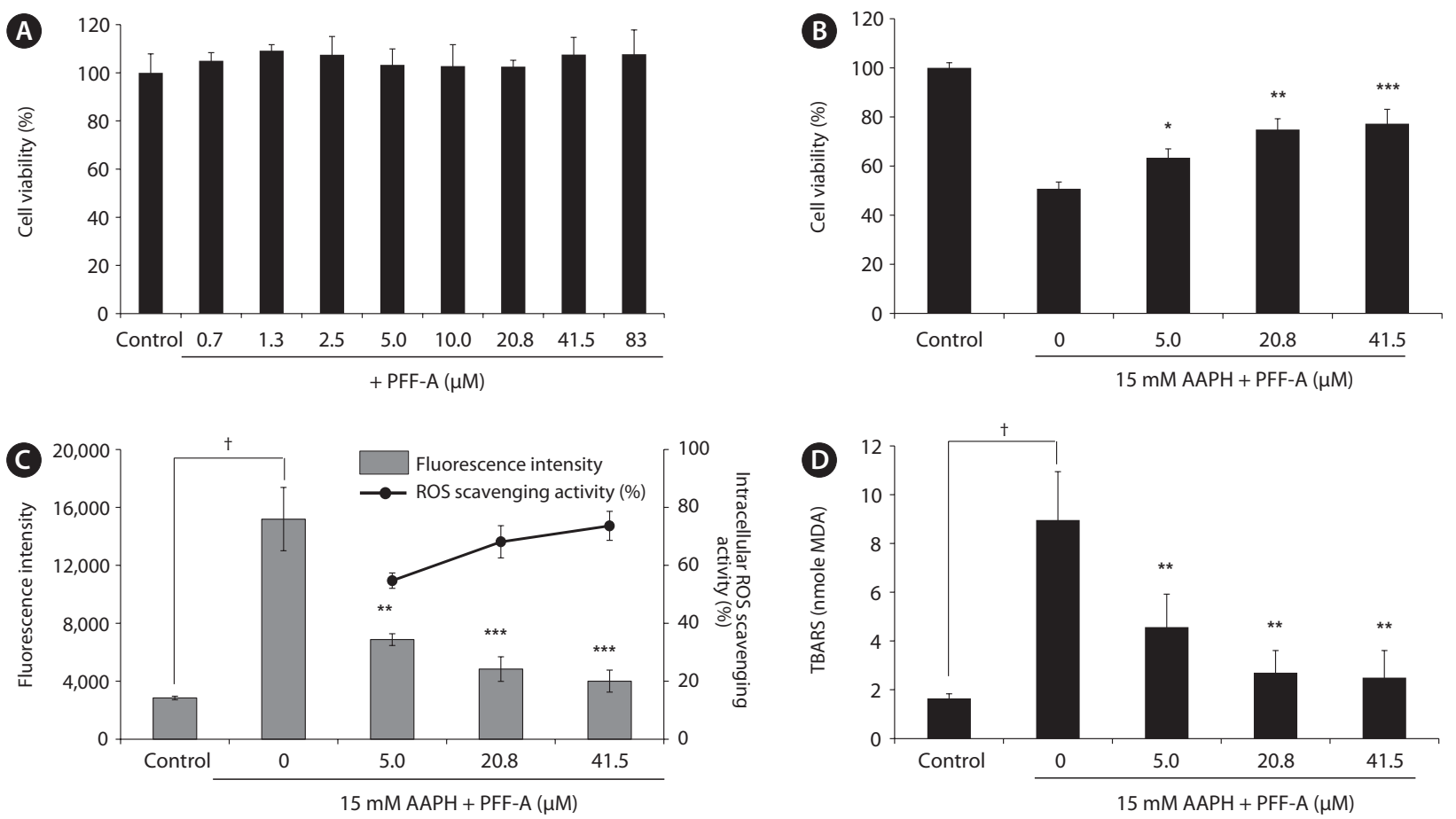

Fig. 2. Cytotoxicity (A) and protective effects of phlorofucofuroeckol-A (PFF-A) isolated from Ecklonia cava against oxidative damage (B), intracellular reactive oxygen species (ROS) (C), and lipid peroxidation (D) induced in 2,2-azobis (2-amidinopropane) dihydrochloride (AAPH)stimulated Vero cells. Vero cells were seeded in 96-well plate at a concentration of $1.0 \times 10^{5}$ cells $\mathrm{mL}^{-1}$. After $16 \mathrm{~h}$ of incubation time at $37^{\circ} \mathrm{C}$ the cells were treated with $10 \mu \mathrm{L}$ of different concentrations of the sample $\left(3,12.5\right.$, and $\left.25 \mu \mathrm{g} \mathrm{mL}^{-1}\right)$ and incubated at $37^{\circ} \mathrm{C}$ under a humidified atmosphere. After $2 \mathrm{~h}$, AAPH was added at a concentration of $15 \mathrm{mM}$. (A) The viability of cells on only PFF-A treatment was determined by MTT assay. (B) The viability of cells on both AAPH and PFF-A treatments was determined by MTT assay. (C) The intracellular ROS generated was detected by dichloro-dihydro-fluorescein diacetate assay. (D) The thiobarbituric acid reacting substances generated was detected by arylesterase / paraoxonase assay kit. MDA, malondialdehyde. Results are the mean \pm standard deviation of three assays. Statistical evaluation was performed to compare the experimental groups and only AAPH treated group. ${ }^{*} p<0.05,{ }^{* *} p<0.01$, and ${ }^{* * *} p<0.005$. ${ }^{\dagger}$ Significantly different from control and only AAPH treated Vero cells $(p<0.05)$.

the stained embryos were observed using a fluorescent microscope, which was equipped with a Moticam color digital camera (Motix, Xiamen, China). Cell death was detected in live embryos using acridine orange staining, a nucleic acid selective metachromatic dye that interacts with DNA and RNA by intercalation or electrostatic attractions. The images of stained embryos were observed using a fluorescence microscope, which was equipped with a CoolSNAP-Pro colour digital camera (Olympus).

Table 1. IC $C_{50}$ values on radicals scavenging activities of PFF-A

\begin{tabular}{cccc}
\hline Radicals & DPPH & Hydroxyl & Alkyl \\
\hline IC $_{50}$ values $(\mu \mathrm{M})^{\mathrm{a}}$ & $10.3 \pm 0.0$ & $21.4 \pm 0.0$ & $3.9 \pm 0.0$ \\
\hline
\end{tabular}

PFF-A, phlorofucofuroeckol-A; DPPH, 2,2-diphenyl-1-picrylhydrazyl. ${ }^{a}$ Inhibitory activities were expressed as the $50 \%$ inhibitory concentrations obtained by interpolation of concentration-inhibition curve. Results are the mean \pm standard deivation of three assays.

\section{Statistical analysis}

All the measurements were made in triplicate and all values were represented as means \pm standard error. The results were subjected to an analysis of the variance (ANOVA) using the Tukey test to analyze the difference. A value of $p<0.05$ was considered to indicate statistical significance.

\section{RESULTS}

\section{Antioxidative activity of PFF-A}

The antioxdative effect of PFF-A, isolated from E. cava, against DPPH, hydroxyl, and alkyl radicals measured by ESR is described in Table 1. As shown in the table, PFF-A exhibited the highest scavenging effect against alkyl radi- 
cals with an $\mathrm{IC}_{50}$ value of $3.9 \mu \mathrm{M}$, while its DPPH and hydroxyl radical scavenging activity had IC $_{50}$ values of 10.3 and $21.4 \mu \mathrm{M}$, respectively.

\section{Cytotoxicity and protective effects of PFF-A against oxidative stress in AAPH-stimulated Vero cells}

PFF-A was no toxic in the cells at all the concentrations used (Fig. 2A), therefore, the effects of PFF-A on cell viability in AAPH-stimulated Vero cells were measured via the MTT assay. The AAPH-stimulated cells without PFFA (positive control) showed a cell survival rate of $48.7 \%$, while the viabilities of cells pre-treated with PFF-A prior to AAPH treatment were increased in a dose dependent manner under non-cytotoxic conditions (Fig. 2B). The PFF-A pre-treated cells exhibited cell survival rates of 61 , 77 , and $79 \%$ at the concentrations of 5.0, 20.8, and 41.5 $\mu \mathrm{M}$, respectively, compared to AAPH-stimulated cells. The scavenging efficacy of PFF-A on ROS production in AAPH-stimulated Vero cells was measured by the DCFHDA assay and results are described in Fig. 2C. As shown in the figure, the generation of intracellular ROS in Vero cells was increased to a fluorescence intensity of 15117 after the treatment with $15 \mathrm{mM} \mathrm{AAPH}$ comparing to non-treated cells. The cells treated with PFF-A inhibited ROS accumulation in a dose-dependent manner. Compared to the ROS levels in cells treated with AAPH alone, co-treatment of AAPH-stimulated cells with PFF-A at a concentration of $20.8 \mu \mathrm{M}$ significantly reduced the ROS fluorescence intensity to 4371 . Notably, the treatment with $41.5 \mu \mathrm{M}$ of PFF-A resulted in a significantly increased intracellular ROS scavenging activity to $77.4 \%$.

\section{Protective effects of PFF-A against lipid peroxi- dation in AAPH-stimulated Vero cells}

As shown in Fig. 2D, the inhibitory effect of PFF-A on lipid peroxidation of AAPH-stimulated Vero cells was determined by measuring TBARS, which is a lipid peroxidation product. When Vero cells were incubated with $15 \mathrm{mM}$ AAPH for $2 \mathrm{~h}$, TBARS was remarkably increased in comparison to the non-treated cells. Co-treatment of 5.0 $\mu \mathrm{M}$ PFF-A with AAPH remarkably inhibited TBARS formation, indicating that PFF-A may provide protection against lipid peroxidation. When the cells were treated with $5.0 \mu \mathrm{M}$ PFF-A, TBARS was remarkably decreased by $4.3 \mathrm{nmol}$ malondialdehyde (MDA).

\section{Inhibitory effects of PFF-A against apoptosis induced in AAPH-stimulated Vero cells}

To evaluate the protective effects of phlorotannins on apoptosis induced by AAPH, the nuclei of Vero cells were stained with Hoechst 33342 for microscopic analysis. Apoptotic bodies induced in Vero cells by AAPH treatment are shown in Fig. 3A. As shown in the figure, when the cells were treated with only AAPH a dramatic increase in nuclear fragmentation was observed as compared to non-treated cells, whereas treatment of PFF-A reduced the numbers of apoptotic bodies in a dose dependent manner. The Bcl-2 family plays an important regulatory role in apoptosis, either as an inhibitor (Bcl-xL) or as an activator (Bax) (Cory and Adams 1998). The pro-apoptosis proteins, Bax and caspase- 3 , and the anti-apoptosis protein, Bcl-xL, were measured by western blot and the results are shown in Fig. 3B. AAPH treatment strongly increased expression of the pro-apoptosis proteins Bax and cleaved caspase-3, whereas the PFF-A treatment dose-dependently decreased Bax and cleaved caspase-3 expression. Additionally, PFF-A treatment increased the $\mathrm{Bcl}-\mathrm{xL}$ protein which was decreased by AAPH treatment.

\section{Protective effects of PFF-A against ROS, cell death, and lipid peroxidation in AAPH-stimulat- ed zebrafish embryo}

The protective effect of PFF-A against oxidative stress in AAPH-stimulated zebrafish embryos is shown in Fig. 4A. AAPH treatment increased the fluorescence of DCFHDA by two-fold, compared to the non-treated group, while PFF-A treatment significantly decreased the ROS levels raized by AAPH under non-toxic conditions. Additionally, cell death in AAPH-stimulated zebrafish embryos was also decreased in a dose-dependent manner upon co-treatment with PFF-A (Fig. 4B). Lipid peroxidation in AAPH-stimulated zebrafish embryo was measured by the diphenyl-1-pyrenylphosphine (DPPP) assay and the results are shown in Fig. 4C. PFF-A dose-dependently decreased the quantification of DPPP fluorescence intensity. The results indicate that co-treatment with PFFA significantly decreased lipid peroxidation induced by AAPH treatment. 

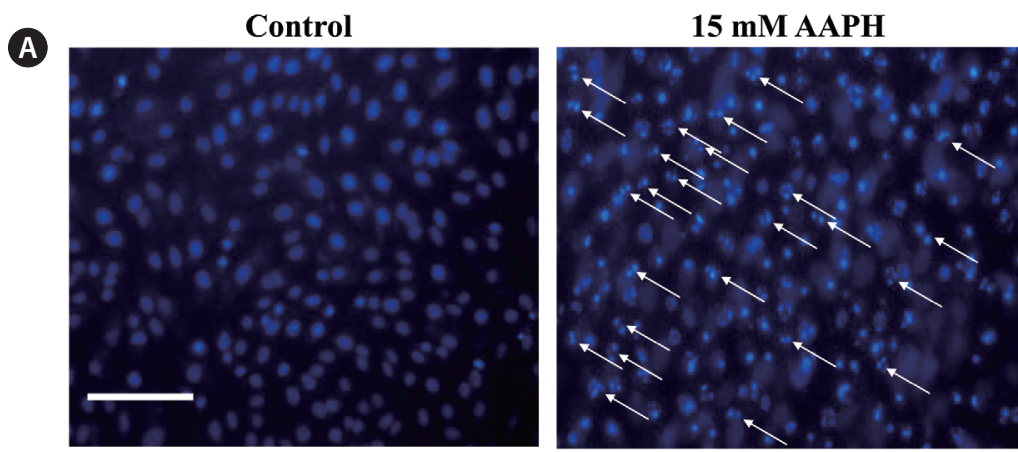

$15 \mathrm{mM}$ АAPH + 5.0 $\mu$ M PFF-A

15 mM AAPH + $20.8 \mu M$ PFF-A
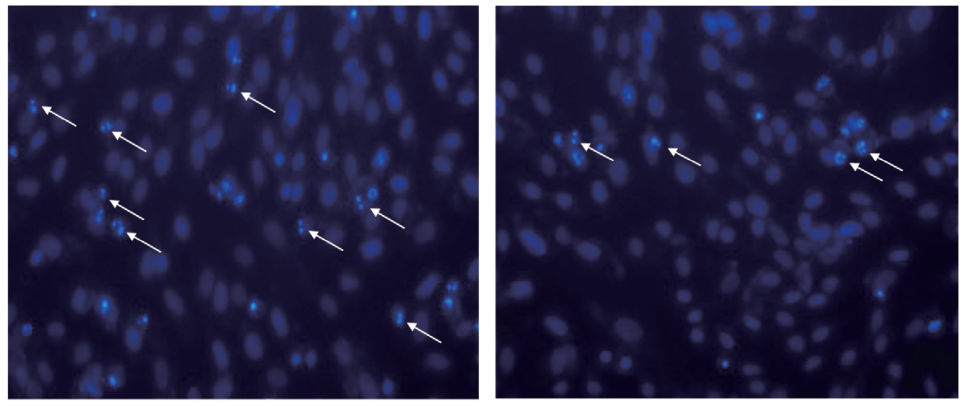

\section{5 mM AAPH + 41.5 $\mu$ M PFF-A}

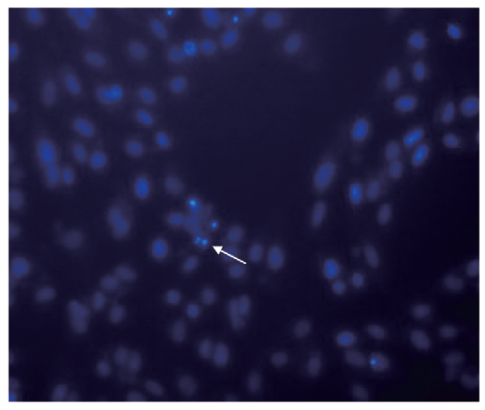

B

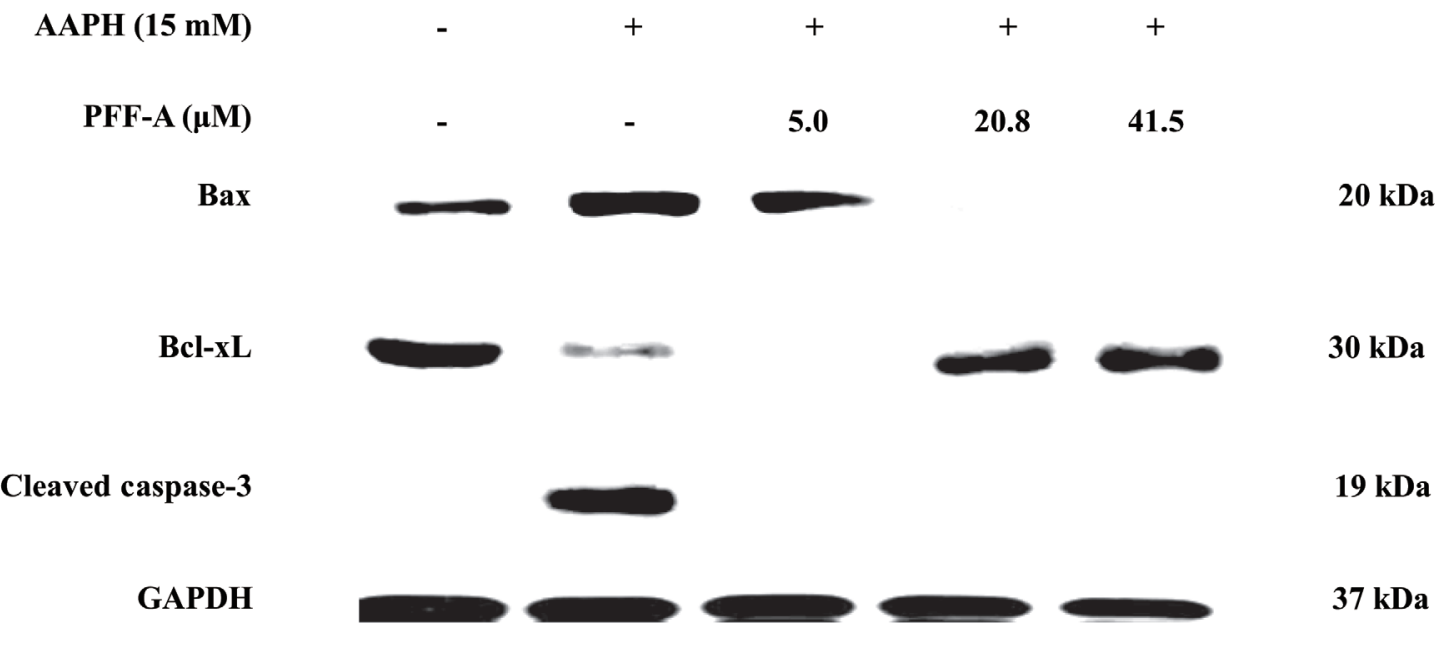

Fig. 3. Inhibitory activities of phlorofucofuroeckol-A (PFF-A) against apoptotic body induced in 2,2-azobis (2-amidinopropane) dihydrochloride (AAPH)-stimulated Vero cells (A) and its inhibitory activities of pro-and anti-apoptosis protease such as Bax, Bcl-xL, and cleaved caspase-3 (B). (A) Vero cells were treated with present or absence of AAPH or present of AAPH + PFF-A were stained with Hoechst 33342 and then observed under a fluorescent microscope using a blue filter (scale $1: 100$ ). (B) Lysates of Vero cells were treated with present or absence of AAPH or present of $\mathrm{AAPH}+\mathrm{PFF}-\mathrm{A}$ were resolved by sodium dodecyl sulfate-polyacrylamide gels and probed with specific antibody (anti-Bax, anti-Bcl-xL, and anticleaved caspase 3). GAPDH, glyceraldehyde 3-phosphate dehydrogenase. Arrows indicate a typical apoptotic cell with apoptotic body. Scale bar represents: $1.0 \mathrm{~mm}$. 

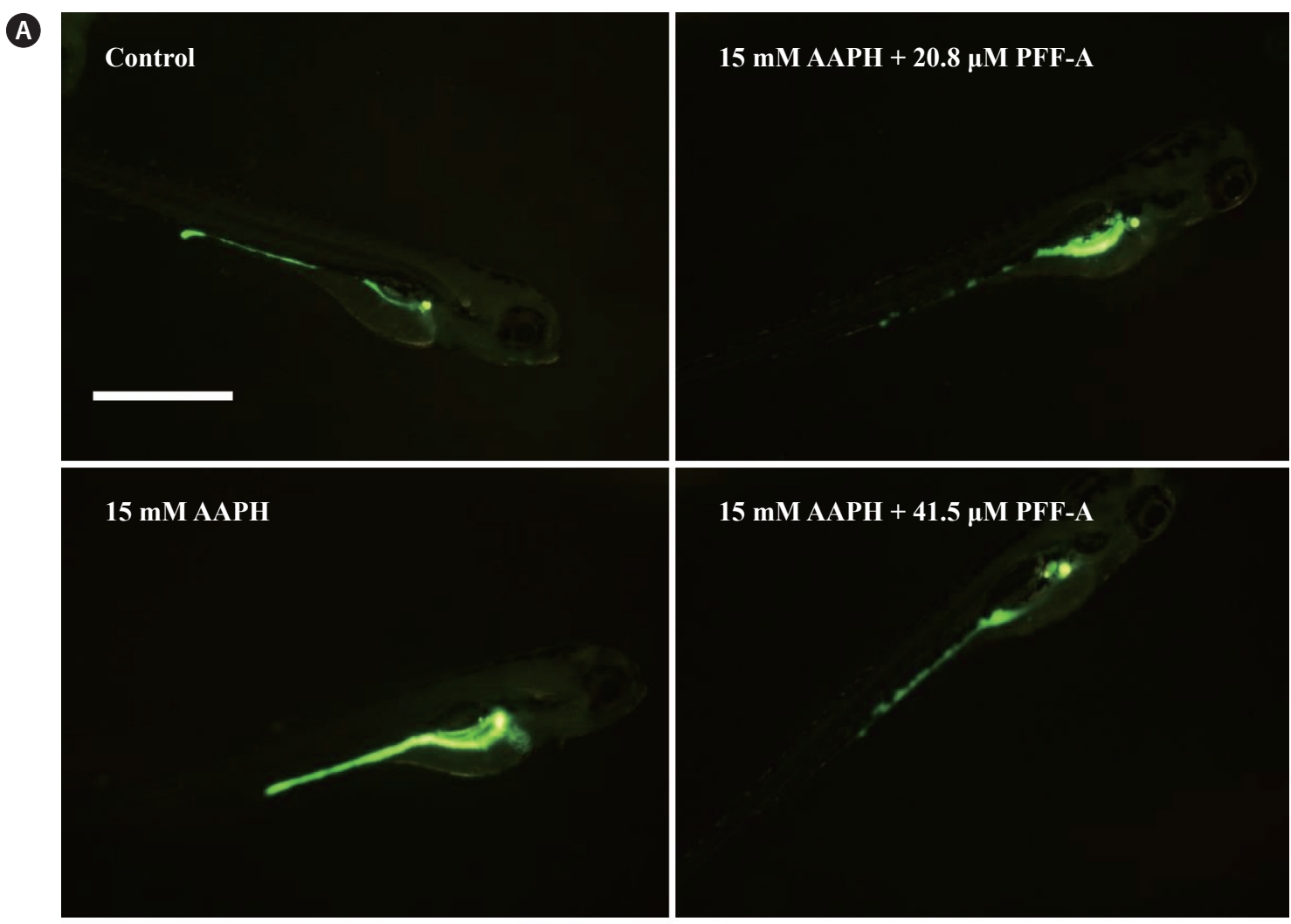

\section{5 mM AAPH + $5.0 \mu \mathrm{M}$ PFF-A}
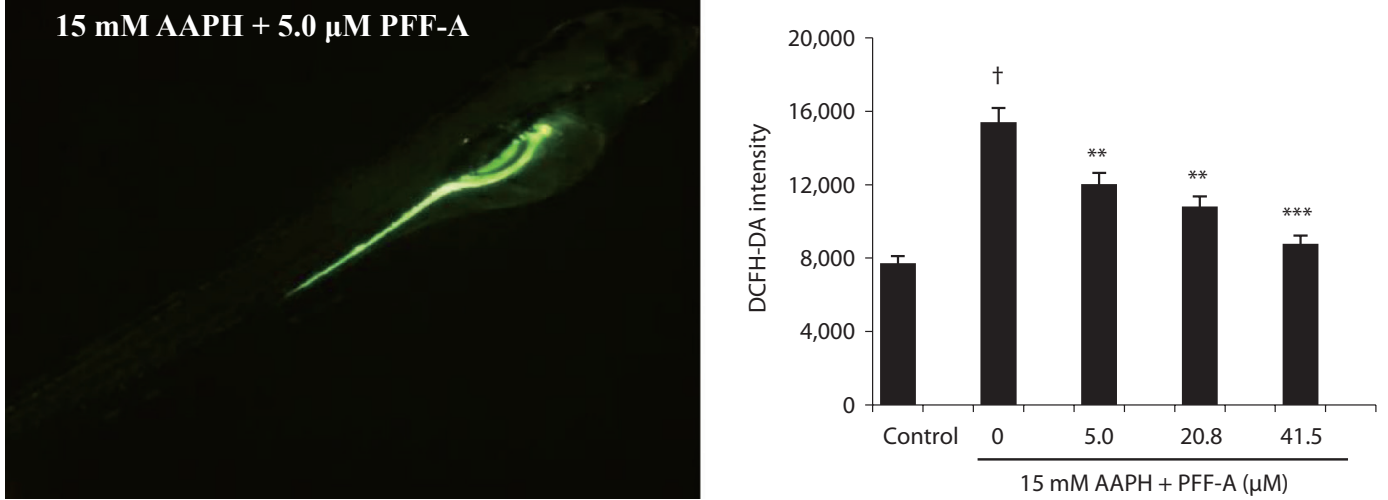

Fig. 4. Protective effects of phlorofucofuroeckol-A (PFF-A) isolated from Ecklonia cava against reactive oxygen species (A), cell death (B), and lipid peroxidation (C) induced in 2,2-azobis (2-amidinopropane) dihydrochloride (AAPH)-stimulated zebrafish embryos. Zebrafish was treated with AAPH or AAPH + PFF-A after 12 hpf. (A) At 2 dpf, individual zebrafish embryo fluorescence intensity was quantified using a Perkin-Elmer LS-5B spectrofluorometer after treatment of dichloro-dihydro-fluorescein diacetate (DCFH-DA) for $1 \mathrm{~h}$. (B) At 2 dpf, individual zebrafish embryo fluorescence intensity was quantified using a Perkin-Elmer LS-5B spectro-fluorometer after treatment of acridine orange solution $\left(7 \mu \mathrm{gL} \mathrm{L}^{-1}\right)$ for $30 \mathrm{~min}$. (C) At $2 \mathrm{dpf}$, individual zebrafish embryo fluorescence intensity was quantified using a Perkin-Elmer LS-5B spectrofluorometer after treatment of diphenyl-1-pyrenylphosphine (DPPP) solution $\left(25 \mu \mathrm{gLL}^{-1}\right)$ for $1 \mathrm{~h}$. Zebrafish embryos were analysed with a fluorescence microscope (scale $1: 100$ ). Results are the mean \pm standard deviation of three assays. Statistical evaluation was performed to compare the experimental groups and only AAPH treated group. ${ }^{*} p<0.05{ }^{* *} p<0.01$, and ${ }^{* * *} p<0.005$. ${ }^{\dagger}$ Significantly different from control and only AAPH treated zebrafish ( $p$ $<0.05)$. Scale bar represents: $1.0 \mathrm{~mm}$. 

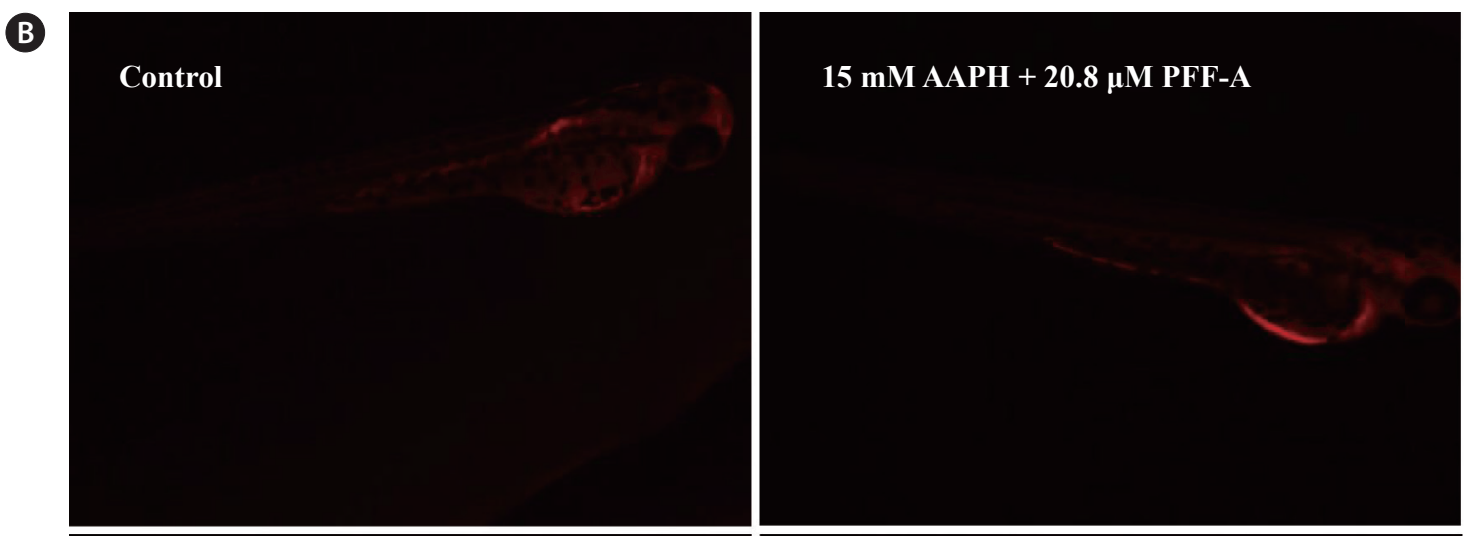

15 mM AAPH

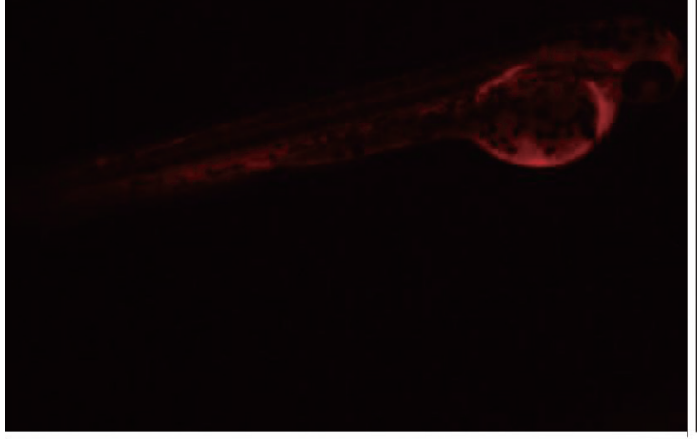

$15 \mathrm{mM}$ AAPH $+5.0 \mu \mathrm{M}$ PFF-A

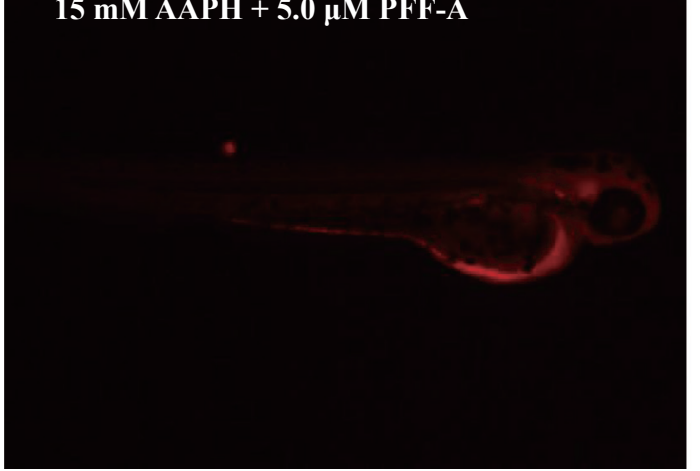

$15 \mathrm{mM}$ AAPH $+41.5 \mu \mathrm{M}$ PFF-A
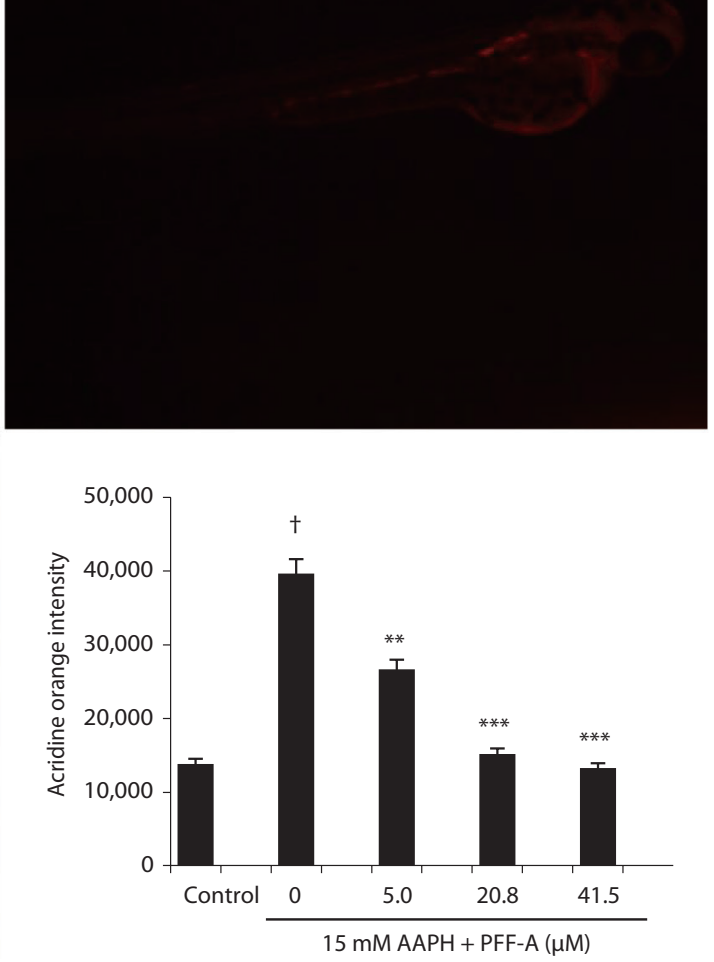

Fig. 4. Continued.

\section{DISCUSSION}

The accumulation of ROS by variable oxidative stress such as smoke, virus, bacteria, and ultra-radiation, etc., results in lipid peroxidation, protein oxidation, DNA damage, and ultimately cell death. AAPH is a water-soluble azo compound widely used as a source of peroxyl radicals $(\mathrm{ROO} \bullet)$, which were generated by thermal decomposition of the azo compound in oxygen (Niki 1990, Mayo et al. 2003). E. cava used for this study contains various phlorotannins such as eckol, 6,6-bieckol, dieckol, and PFF-A, etc. The phlorotannins have been known to have strong antioxidant activity against DPPH, hydroxyl, and peroxyl radicals. Among them, dieckol exhibits the strongest antioxidant effect with recorded $\mathrm{IC}_{50}$ values of 8.3, 28.6, and $14.5 \mu \mathrm{M}$, against DPPH, hydroxyl, and alkyl radicals, respectively. Additionally, PFF-A showed a strong antioxidant effect $\left(\mathrm{IC}_{50}\right.$ values: 17.7, 39.2, and 21.4 $\mu \mathrm{M}$, respectively) (Li et al. 2009). However, PFF-A isolated from E. cava in this study showed relatively stronger radical scavenging activities $\left(\mathrm{IC}_{50}\right.$ values: 10.3, 21.4, and 3.9 $\mu \mathrm{M}$, respectively) than the previous results. In particu- 


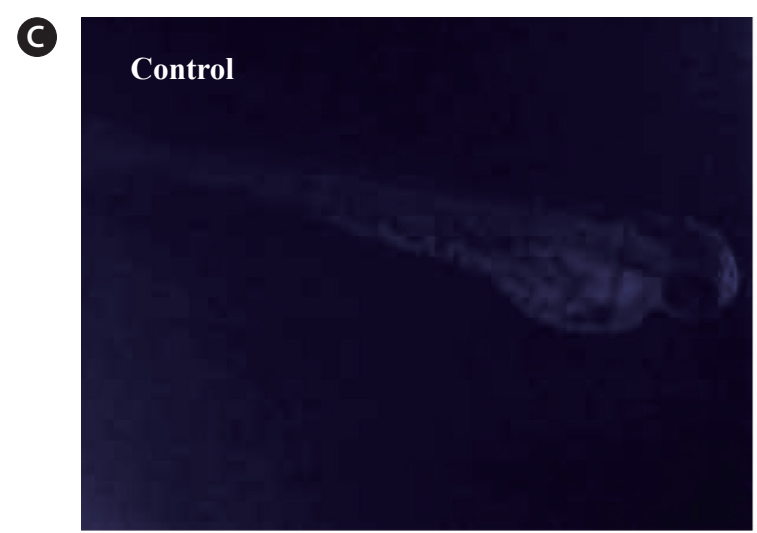

15 mM AAPH

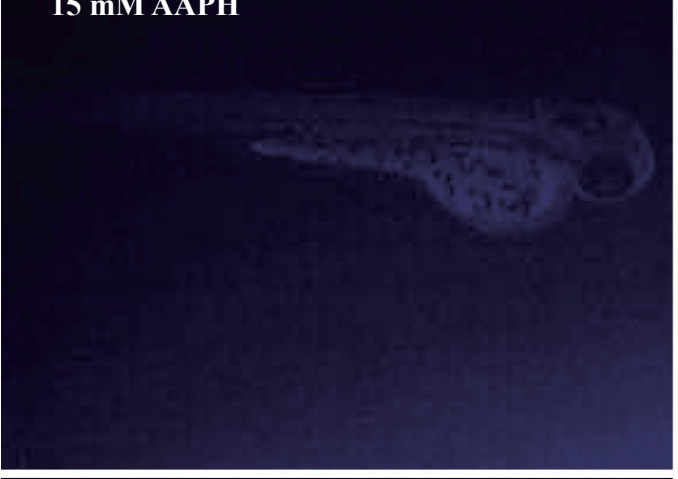

$15 \mathrm{mM}$ AAPH $+5.0 \mu \mathrm{M}$ PFF-A

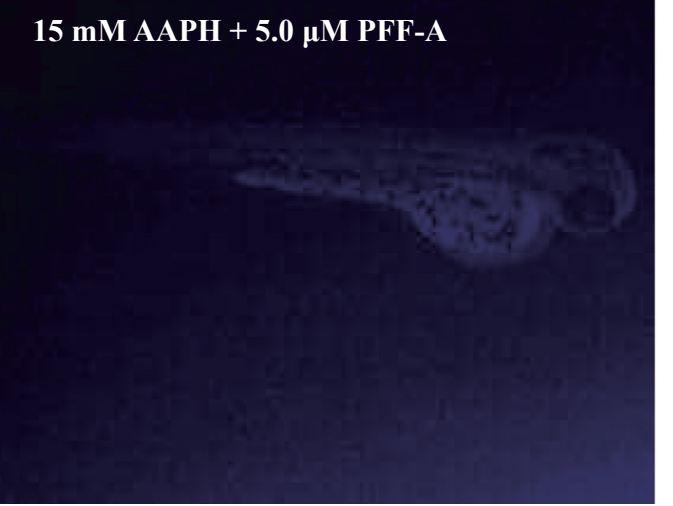

Fig. 4. Continued.

lar, the peroxyl radical scavenging activity of PFF-A was shown to be the highest. These results indicated that PFFA would have a protective effect against peroxyl radicals induced by AAPH.

Lipid peroxidation in biological systems has long been thought of as a toxicological phenomenon that results in pathological consequences and AAPH enhanced lipid peroxidation in cellular systems (Yokozawa et al. 2000). Consistent with these views, we measured the lipid peroxidant, MDA, to determine the antioxidant function of PFF-A against AAPH-induced cellular damage in Vero
15 mM AAPH $+20.8 \mu \mathrm{M}$ PFF-A

15 mM AAPH + 41.5 $\mu$ M PFF-A

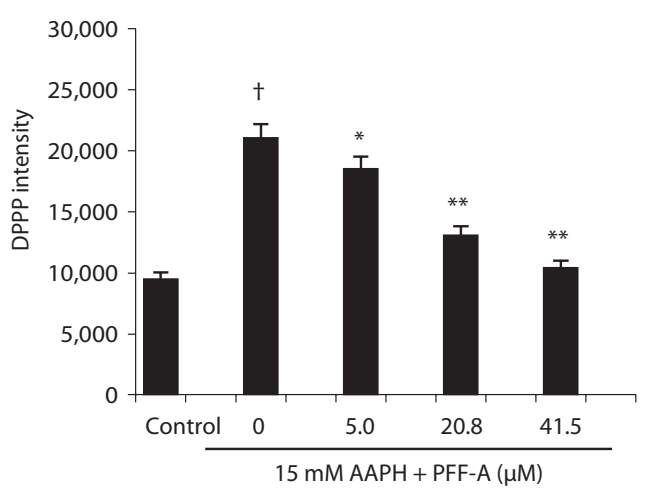

cells. In these results, PFF-A decreased AAPH-induced MDA formation in Vero cells. Thus, PFF-A prevented the accumulation of excessive free radicals and protected the Vero cells from AAPH-derived cellular injury.

Many of the agents that induce apoptosis are oxidants or stimulators of cellular oxidative metabolism, whereas antioxidants prevent apoptosis in some systems (Qin et al. 2001, Sakr and Abel-Samie 2008). Studies recently reported that $\mathrm{Bcl}-\mathrm{xL}$ protein is also responsible for cellular defense against oxidative stress. In addition, the activation of Bcl-xL can inhibit lipid peroxidation. These facts 
indicate that the anti-apoptotic Bcl-xL protein is associated with mitochondrial membrane integrity by preventing capase- 3 activation, Bax redistribution, and apoptosis (Er et al. 2006). In this study, PFF-A reduces apoptosis, via up-regulation of Bcl-xL and down- regulation of Bax and caspase- 3 expression. The results indicate that PFFA generates anti-lipid peroxidation by blocking apoptosis in Vero cells.

In zebrafish systems, we evaluated lipid peroxidation by a fluorescent probe DPPP. DPPP is non-fluorescent, but it becomes fluorescent for detection when the cell membrane lipid is peroxidized. Cell death was detected in zebrafish by staining with acridine orange, a nucleic acid specific metachromatic dye (Ko et al. 2014). Previous studies reported that AAPH-induced lipid peroxidation in zebrafish embryos was decreased by various phlorotannins from E. cava such as dieckol, eckol, triphlorethol A, eckstolonol, and phloroglucinol. The phlorotannins decreased the cell death generated in zebrafish embryos by stimulation of AAPH (Kang et al. 2013). In this study, we suggest that PFF-A, one of phlorotannins from E. cava, also possesses a strong protective effect against lipid peroxidation and cell death induced in zebrafish embryos by AAPH.

The free radicals generated from AAPH rapidly react with oxygen molecules to yield peroxyl radicals (Kang et al. 2012a). The lipid peroxyl radicals then attack other lipid molecules to form lipid hydroperoxide and new lipid radicals. This reaction takes place repeatedly with resultant attacks upon various biological molecules, and it induces physiochemical alterations and cellular damage (Miki et al. 1987). Due to this, PFF-A with strong peroxyl radical scavenging activity would protect our body from the damage of lipid peroxidation.

Consequently, this study investigated that PFF-A isolated from E. cava showed strong protective effects against lipid peroxidation induced in vitro and in vivo by AAPH. Therefore, PFF-A may be useful as a functional supplement for anti-lipid peroxidation.

\section{ACKNOWLEDGEMENTS}

We would like to thank Kil Nam Kim and his team members for help with LC-ESI/MS analysis (Jeju Center, Korea Basic Science Institute, Korea). This research was supported by the Ministry of Agriculture, Food and Rural Affairs (MAFRA), Ministry of Oceans and Fisheries (MOF), Rural Development Administration (RDA), and Korea Forest Service (KFS) (213004-04-2-SB930).

\section{REFERENCES}

Artan, M., Li, Y., Karadeniz, F., Lee, S. -H., Kim, M. -M. \& Kim, S. -K. 2008. Anti-HIV-1 activity of phloroglucinol derivative, 6,6'-bieckol, from Ecklonia cava. Bioorg. Med. Chem. 16:7921-7926.

Bast, A., Haenen, G. R. M. M. \& Doelman, C. J. A. 1991. Oxidants and antioxidants: state of the art. Am. J. Med. 91(Suppl. 3):S2-S13.

Cory, S. \& Adams, J. M. 1998. Matters of life and death: programmed cell death at Cold Spring Harbor. Biochim. Biophys. Acta 1377:R25-R44.

Eom, S. -H., Kim, Y. -M. \& Kim, S. -K. 2012. Antimicrobial effect of phlorotannins from marine brown algae. Food Chem. Toxicol. 50:3251-3255.

Er, E., Oliver, L., Cartron, P. -F., Juin, P., Manon, S. \& Vallette, F. M. 2006. Mitochondria as the target of the pro-apoptotic protein Bax. Biochim. Biophys. Acta 1757:1301-1311.

Esterbauer, H., Gebicki, J., Puhl, H. \& Jürgens, G. 1992. The role of lipid peroxidation and antioxidants in oxidative modification of LDL. Free Radic. Biol. Med. 13:341-390.

Faure, P., Oziol, L., Artur, Y. \& Chomard, P. 2004. Thyroid hormone (T3) and its acetic derivative (TA3) protect lowdensity lipoproteins from oxidation by different mechanisms. Biochimie 86:411-418.

Halliwell, B., Hu, M. L., Louie, S., Duvall, T. R., Tarkington, B. K., Motchnik, P. \& Cross, C. E. 1992. Interaction of nitrogen dioxide with human plasma: antioxidant depletion and oxidative damage. FEBS Lett. 313:62-66.

Heath, R. L. \& Packer, L. 1968. Photoperoxidation in isolated chloroplasts: I. Kinetics and stoichiometry of fatty acid peroxidation. Arch. Biochem. Biophys. 125:189-198.

Hu, C. \& Kitts, D. D. 2005. Dandelion (Taraxacum officinale) flower extract suppresses both reactive oxygen species and nitric oxide and prevents lipid oxidation in vitro. Phytomedicine 12:588-597.

Jain, K., Kataria, S. \& Guruprasad, K. N. 2003. Changes in antioxidant defenses of cucumber cotyledons in response to UV-B and to the free radical generating compound AAPH. Plant Sci. 165:551-557.

Kang, K. S., Kim, H. Y., Yoo, H. H., Piao, X. L., Ham, J., Yang, H. O. \& Park, J. H. 2012a. Protective effect of ginseng sapogenins against 2,2' -azobis (1-aminopropane) dihydrochloride (AAPH)-induced LLC-PK 1 cell damage. Bioorg. Med. Chem. Lett. 22:634-637.

Kang, M. -C., Cha, S. H., Wijesinghe, W. A. J. P., Kang, S. -M., Lee, S. -H., Kim, E. -A., Song, C. B. \& Jeon, Y. -J. 2013. Protective effect of marine algae phlorotannins against AAPH-induced oxidative stress in zebrafish embryo. Food Chem. 138:950-955. 
Kang, S. -M., Heo, S. -J., Kim, K. -N., Lee, S. -H. \& Jeon, Y. -J. $2012 b$. Isolation and identification of new compound, 2,7"-phloroglucinol-6,6'-bieckol from brown algae, Ecklonia cava and its antioxidant effect. J. Funct. Foods 4:158-166

Kim, A. -R., Lee, M. -S., Shin, T. -S., Hua, H., Jang, B. -C., Choi, J. -S., Byun, D. -S., Utsuki, T., Ingram, D. \& Kim, H. -R. 2011. Phlorofucofuroeckol A inhibits the LPS-stimulated iNOS and COX-2 expressions in macrophages via inhibition of NF- $\kappa$ B, Akt, and p38 MAPK. Toxicol. In Vitro 25:1789-1795.

Kim, H. K. 2014. Role of ERK/MAPK signalling pathway in anti-inflammatory effects of Ecklonia cava in activated human mast cell line-1 cells. Asian Pac. J. Trop. Med. 7:703-708.

Ko, J. -Y., Kim, E. -A., Lee, J. -H., Kang, M. -C., Lee, J. -S., Kim, J. -S., Jung, W. -K. \& Jeon, Y. -J. 2014. Protective effect of aquacultured flounder fish-derived peptide against oxidative stress in zebrafish. Fish Shellfish Immunol. 36:320-323.

Ko, S. -C., Lee, M., Lee, J. -H., Lee, S. -H., Lim, Y. \& Jeon, Y. -J. 2013. Dieckol, a phlorotannin isolated from a brown seaweed, Ecklonia cava, inhibits adipogenesis through AMP-activated protein kinase (AMPK) activation in 3T3L1 preadipocytes. Environ. Toxicol. Pharmacol. 36:12531260.

Le, Q. -T., Li, Y., Qian, Z. -J., Kim, M. -M. \& Kim, S. -K. 2009. Inhibitory effects of polyphenols isolated from marine alga Ecklonia cava on histamine release. Proc. Biochem. 44:168-176.

Lee, J. -H., Ko, J. -Y., Oh, J. -Y., Kim, C. -Y., Lee, H. -J., Kim, J. \& Jeon, Y. -J. 2014. Preparative isolation and purification of phlorotannins from Ecklonia cava using centrifugal partition chromatography by one-step. Food Chem. 158:433-437.

Lee, J. -H., Zhang, C., Ko, J. -Y., Lee, J. -S. \& Jeon, Y. -J. 2015. Evaluation on anticancer effect against HL-60 cells and toxicity in vitro and in vivo of the phenethyl acetate isolated from a marine bacterium, Streptomyces griseus.
Fish. Aquat. Sci. 18:35-44.

Lee, S. -H., Kang, M. -C., Moon, S. -H., Jeon, B. -T. \& Jeon, Y. -J. 2013. Potential use of ultrasound in antioxidant extraction from Ecklonia cava. Algae 28:371-378.

Li, Y., Qian, Z. -J., Ryu, B. M., Lee, S. -H., Kim, M. -M. \& Kim, S. -K. 2009. Chemical components and its antioxidant properties in vitro: an edible marine brown alga, Ecklonia cava. Bioorg. Med. Chem. 17:1963-1973.

Ling, J., Wei, B., Lv, G., Ji, H. \& Li, S. 2012. Anti-hyperlipidaemic and antioxidant effects of turmeric oil in hyperlipidaemic rats. Food Chem. 130:229-235.

Mayo, J. C., Tan, D. X., Sainz, R. M., Natarajan, M., Lopez-Burillo, S. \& Reiter, R. J. 2003. Protection against oxidative protein damage induced by metal-catalyzed reaction or alkylperoxyl radicals: comparative effects of melatonin and other antioxidants. Biochim. Biophys. Acta 1620:139-150.

Miki, M., Tamai, H., Mino, M., Yamamoto, Y. \& Niki, E. 1987. Free-radical chain oxidation of rat red blood cells by molecular oxygen and its inhibition by $\alpha$-tocopherol. Arch. Biochem. Biophys. 258:373-380.

Niki, E. 1990. Free radical initiators as source of water- or lipid-soluble peroxyl radicals. Methods Enzymol. 186:100108.

Qin, F, Rounds, N. K., Mao, W., Kawai, K. \& Liang, C. S. 2001. Antioxidant vitamins prevent cardiomyocyte apoptosis produced by norepinephrine infusion in ferrets. Cardiovasc. Res. 51:736-748.

Sakr, S. A. \& Abel-Samie, H. A. 2008. Apoptosis related protein Bax in liver of metalazxyl fungicide-treated mice: the effect of antox. Ozean J. Appl. Sci. 1:17-27.

Shim, S. -Y., Choi, J. -S. \& Byun, D. -S. 2009. Inhibitory effects of phloroglucinol derivatives isolated from Ecklonia stolonifera on FceRI expression. Bioorg. Med. Chem. 17:4734-4739.

Yokozawa, T., Liu, Z. W. \& Chen, C. P. 2000. Protective effects of Glycyrrhizae radix extract and its compounds in a renal hypoxia (ischemia)-reoxygenation (reperfusion) model. Phytomedicine 6:439-445. 